\title{
Erratum to: Energy Release Channels During Destruction of Impurity-Helium Condensates
}

\author{
V.V. Khmelenko • A.A. Pelmenev • \\ I.N. Krushinskaya • I.B. Bykhalo • R.E. Boltnev • \\ D.M. Lee
}

Published online: 22 September 2012

(C) Springer Science+Business Media New York 2012

\section{Erratum to: J Low Temp Phys DOI 10.1007/s10909-012-0707-3}

Following are corrections to the original article. The publisher regrets the errors.

1. Section 2.1, second paragraph, fifth line. Sentence is correct as follows:

The $\alpha^{\prime}$-group corresponds to the electronic transition $\mathrm{N}\left({ }^{2} \mathrm{D} \rightarrow{ }^{4} \mathrm{~S}\right)$ accompanied by a simultaneous vibrational excitation $v=0 \rightarrow v=1$ in the neighbouring $\mathrm{N}_{2}\left(\mathrm{X}^{1} \Sigma_{g}^{+}\right)$molecule.

2. Section 2.2, line 12:

a-group and g-line are corrected as $\alpha$-group and $\gamma$-line.

3. Section 3 , second paragraph, line 6 :

$\mathrm{W}^{3} \Delta_{\mathrm{u}}^{-}\left(v^{\prime \prime}=4\right) \rightarrow \mathrm{A}^{3} \Sigma_{\mathrm{u}}^{+}\left(v^{\prime}=0-4\right) \quad$ is corrected to $\mathrm{W}^{3} \Delta_{\mathrm{u}}\left(v^{\prime \prime}=4\right) \rightarrow$ $\mathrm{A}^{3} \Sigma_{\mathrm{u}}^{+}\left(v^{\prime}=0-4\right)$

4. Section 3, second paragraph, line 16 :

$\mathrm{W}^{3} \Delta_{\mathrm{u}}^{-}$is corrected to $\mathrm{W}^{3} \Delta_{\mathrm{u}}$

5. Updated Ref. 2 is as follows:

V.V. Khmelenko, I.N. Krushinskaya, R.E. Boltnev, I.B. Bykhalo, A.A. Pelmenev, D.M. Lee, Low Temp. Phys. 38, 871 (2012).

The online version of the original article can be found under doi:10.1007/s10909-012-0707-3.

V.V. Khmelenko $(\varangle) \cdot$ D.M. Lee

Department of Physics and Astronomy, Texas A\&M University, College Station, TX 77843, USA

e-mail:khmel@physics.tamu.edu

A.A. Pelmenev · I.N. Krushinskaya · I.B. Bykhalo · R.E. Boltnev

Branch of Institute of Energy Problems of Chemical Physics RAS, Chernogolovka, Moscow region, 142432, Russia 
6. Updated Ref. 4 is as follows:

S. Mao, R.E. Boltnev, V.V. Khmelenko, D.M. Lee, Low Temp. Phys. 38 (2012) (accepted for publication). 